OPEN ACCESS

Edited by:

Jian Zhou,

Fudan University, China

Reviewed by:

Marco Massani,

ULSS2 Marca Trevigiana, Italy

Antonio Facciorusso,

University of Foggia, Italy

${ }^{*}$ Correspondence:

Lequn $\mathrm{Li}$

lilequngx@163.com

Jiazhou Ye

nnsz20013@163.com

${ }^{\dagger}$ These authors have contributed equally to this work

Specialty section:

This article was submitted to

Surgical Oncology,

a section of the journa

Frontiers in Oncology

Received: 13 July 2021 Accepted: 28 October 2021 Published: 19 November 2021

Citation:

Chen X, Lai L, Ye J and Li L (2021) Downstaging Therapies for Unresectable Hepatocellular

Carcinoma Prior to Hepatic

Resection: A Systematic

Review and Meta-Analysis.

Front. Oncol. 11:740762.

doi: 10.3389/fonc.2021.740762

\section{Downstaging Therapies for Unresectable Hepatocellular Carcinoma Prior to Hepatic Resection: A Systematic Review and Meta-Analysis}

\author{
Xinyu Chen ${ }^{1,2 \dagger}$, Lin Lai ${ }^{3 \dagger}$, Jiazhou $\mathrm{Ye}^{1 *}$ and Lequn $\mathrm{Li}^{1 *}$ \\ ${ }^{1}$ Department of Hepatobiliary Surgery, Guangxi Medical University Cancer Hospital, Nanning, China, ${ }^{2}$ Department of Medical \\ Oncology, The First Affiliated Hospital of Guangxi Medical University, Nanning, China, ${ }^{3}$ Department of Radiotherapy, Guangxi \\ Medical University Cancer Hospital, Nanning, China
}

Introduction: Hepatocellular carcinoma $(\mathrm{HCC})$ is a high-grade malignant disease with unfavorable prognosis, and although surgical therapy is necessary, not all patients with HCC are suitable candidates for surgery. Downstaging as preoperative therapeutic strategy, which can convert unresectable $\mathrm{HCC}$ into resectable $\mathrm{HCC}$, intends to increase the resection rate and improve prognosis.

Methods: We searched multiple databases updated to December 30, 2020, for studies on transcatheter arterial chemoembolization (TACE), Yttrium 90 microsphere selective internal radiation (SIR)/transcatheter radioembolization (TARE), hepatic arterial infusion $(\mathrm{HAl})$, and systemic treatment as downstaging treatment before resection for patients with unresectable HCC.

Results: A total of 20 comparative and non-comparative studies were finally included in the meta-analysis. The pooled downstaging rate of hepatic resection (HR) was 14\% [95\% confidence interval (Cl) 0.10-0.17] with significant heterogeneity $\left(I^{2}=94.51 \%\right)$. The chemotherapy, combination, and non-cirrhosis groups exhibit higher rates of downstaging, but these differences were not significant. For comparative studies, the overall survival (OS) rates of resection after downstaging were far better than those inpatients who received locoregional therapy (LRT) or systemic treatment alone at 1 year (RR 1.87, 95\% Cl 1.48-2.38), 3 years (RR 5.56, 95\% Cl 2.55-12.10), and 5 years (RR 5.47, 95\% Cl 2.22-13.49). In addition, the pooled disease-free survival (DFS) rates in patients undergoing HR after successful downstaging were $78 \%(95 \% \mathrm{Cl} 0.62-0.93)$ at 1 
year, $47 \%(95 \% \mathrm{Cl} 0.25-0.68)$ at 3 years, and $46 \%(95 \% \mathrm{Cl} 0.32-0.59)$ at 5 years. The pooled OS rates were $88 \%(95 \% \mathrm{Cl} 0.82-0.95)$ at 1 year, $64 \%(95 \% \mathrm{Cl} 0.59-0.69)$ at 3 years, and $42 \%(95 \% \mathrm{Cl} 0.29-0.54)$ at 5 years.

Conclusions: Downstaging may serve as a screening tool to identify patients who might benefit from surgery. Resection after successful downstaging can improve prognosis.

Keywords: hepatic resection (HR), downstaging, hepatocellular carcinoma, unresectable, meta-analysis

\section{INTRODUCTION}

Hepatocellular carcinoma (HCC) is a malignant disease that ranks sixth in morbidity and fourth in fatality among cancers globally (1). Hepatic resection (HR) and liver transplantation (LT) are the main curative-intent options, which offer 5-year survival rate exceeding $70 \%$ in patients with early HCC. However, the application of LT is limited by a shortage of donors. Thus, HR is currently a popular curative therapy. The indications for $\mathrm{HR}$ in treating HCC remain controversial. According to guidelines from the European Association for the Study of the Liver (EASL) (2), American Association for the Study of Liver Disease (AASLD) (3), and National Comprehensive Cancer Network (NCCN) (4), following the Barcelona Clinic Liver Cancer (BCLC) system (5), only patients with stage A are resectable. Unfortunately, based on the indication, most patients miss the time window for surgical therapy, leaving less than $30 \%$ of patients' resectability at the time of diagnosis.

In this context, the indications for HR extend beyond the early stage of HCC in clinical practice (6-8). The Asian Pacific Association for the Study of the Liver (APASL) guidelines set wider indications for HR (9); some patients with BCLC stages $\mathrm{B}-\mathrm{C}$ can be considered candidates for resection in terms of tumor burden and liver functional reserves. Moreover, comprehensive strategies are required to create opportunities for resection. Therapies that include locoregional therapies (LRTs) such as transcatheter arterial chemoembolization (TACE), Yttrium 90 microsphere selective internal radiation (SIR)/transcatheter radioembolization (TARE), hepatic arterial infusion (HAI) for patients with stage $B$, and systemic treatment such as molecular targeting and chemotherapy for patients with stage $\mathrm{C}$ aim at reducing the tumor load and tumor stage to convert unresectable HCC to resectable HCC, or to make it easier to remove the tumor radically; this approach is referred to as downstaging (10). Downstaging strategies are recommended for patients exceeding the Milan criteria considered for LT by the EASL, AASLD, and NCCN (2-4). However, since most studies on downstaging of HR have had small sample sizes, inconsistent inclusion criteria, great difference in results, and lack of prospective clinical trials with large samples, no consensus has been reached yet on HR. There are no systematic reviews or meta-analyses of downstaging prior to HR in patients with advanced unresectable HCC. Therefore, we systematically summarized studies on downstaging therapies for HCC, to synthesize the existing evidence regarding the efficacy of LRT or systemic therapies as downstaging strategies for patients with unresectable HCC who are potential candidates for resection.

\section{MATERIALS AND METHODS}

All methods were performed according to the Preferred Reporting Items for Systematic Reviews and Meta-Analyses (PRISMA) (11) and MOOSE (Meta-analysis of Observational Studies in Epidemiology) (12) reporting guidelines.

\section{Literature Screening and Search Strategy}

We thoroughly searched all relevant studies updated to December 30, 2020, in the PubMed (https://www.ncbi.nlm.nih. gov/pubmed), Cochrane (https://www.cochranelibrary.com), Embase (https://www.embase.com), Web of Science (https:// www.webofknowledge.com), VIP (http://www.cqvip.com), Wanfang (http://www.wanfangdata.com.cn), and CNKI (https://www.cnki.net) database. The search strategy was as follows: [(hepatocellular carcinoma) OR (hepatocellular cancer) OR (liver cancer) OR (hepatic neoplasm)] AND [(downstaging) OR (downstage) OR (down stage) OR (conversion therapy) OR (preoperative treatment) OR (preoperative treatments) OR (preoperative therapy) OR (preoperative therapies)] AND [(hepatic resection) OR (hepatectomy) OR (salvage)].

\section{Study Selection}

Two authors independently conducted the literature search and initially selected relevant studies by reading titles and abstracts. Studies describing irrelevant subjects were excluded from the first step. Furthermore, the remaining studies were further screened by reading the full texts, and ineligible studies were discarded. Our inclusion criteria were as follows: (1) patients who were diagnosed as unresectable HCC, including extrahepatic disease or extensive local disease not amenable to definitive resection; (2) intervention included any treatment for HCC that reduced the tumor load and tumor stage (e.g., TACE, radiofrequency ablation, SIR/TARE, systemic therapy, or a combination of therapies); (3) studies eligible for our metaanalysis included prospective and retrospective comparative studies, cohort observational studies, and case series; and (4) outcomes evaluating rates of success for downstaging, overall survival (OS), disease-free survival (DFS) rate, and recurrence-free survival (RFS) rate. We excluded articles that (1) included less than five patients; (2) reported duplicate cohorts of patients, in which case we used the most updated cohort or the 
most recent publication; (3) were conference proceedings, letters, literature reviews, systematic reviews, case reports, comments, animal experiments, or unpublished studies with no full-text availability; (4) applied no restrictions to the language of articles; (5) reported downstaging used in LT, unless the studies also included a resection group, the data of which could be used to evaluate the downstaging success rate or survival rate could be extracted separately.

\section{Data Extraction}

For each study, data were extracted in duplicate using standardized forms. We extracted the following variables from each study: study characteristics (first author's last name, publication year, study design, and sample size), downstaging treatment modality, downstaging rate, OS rate, and DFS rate. The outcomes we extracted from each study were as follows: (1) the success rate of downstaging to remove tumor completely and (2) the long-term survival for HR with downstaging.

\section{Quality Assessment}

The quality of randomized controlled trials (RCTs) and nonrandomized controlled trials (nRCTs) were assessed using the Cochrane bias assessment tool (13) and methodological index for non-randomized studies (MINORS) (14), respectively. The observational study quality was based on the modified Newcastle-Ottawa scale (NOS) (15). The Institute of Health Economics Quality Appraisal (IHEQA) Checklist (16) was used to assess methodological quality for case series studies without a control group.

\section{Statistical Analysis}

For comparative studies, we calculated the relative risks (RRs) and $95 \%$ confidence intervals (CIs) employing a binomial distribution. For noncomparative studies, we calculated the event rates of outcomes, and we estimated 95\% CIs using Jeffreys method. A heterogeneity test for homogeneity of effect size was also given. Heterogeneity was assessed by $I^{2}$ statistics and the $p$-value of the Chi-square test (17). A random-effects model was used to merge the data and estimate effect-size indicators according to the Cochrane Handbook for Systematic Reviews of Interventions version 6.2 (18). Statistical analysis was conducted using Stata 15.0 software (Stata Corporation, College Station, TX, USA), and a $p$-value $<0.05$ was considered statistically significant for the effect size of each included study.

\section{RESULTS}

\section{Study Characteristics and Quality Assessment}

The flowchart of the study selection process is shown in Figure 1. After searching seven electronic databases, 3,348 citations were retrieved initially, of which 310 for screening titles and abstracts and 66 full-text for reviewing. A total of 20 studies were finally included in the meta-analysis (Table 1). The quality assessment of the included studies is displayed in Supplementary Tables 1-3.
Two prospective single-arm studies had a moderate risk of bias, and six observational studies received NOS scores of $\geq 7$, while 12 case series had a high risk of bias. In total, most inclusive studies were rated as low-moderate quality. There were no RCT identified.

\section{Downstaging Rate}

There were 17 studies (4 comparative studies and 13 noncomparative studies) covering 20 subgroups with 4,878 patients that evaluated downstaging rate. There was only one case-control study comparing two chemotherapy regimens of downstaging; therefore, a single-arm meta-analysis was conducted for the downstaging success rate (Figure 2A). The pooled downstaging rate of $\mathrm{HR}$ was $14 \%(95 \%$ CI $0.10-0.17)$ with significant heterogeneity $\left(I^{2}=94.51 \%\right)$. Subgroup analyses were performed by intervention, mono/multitherapy, and if patients with cirrhosis or extrahepatic spread were included. In the intervention group, data were sufficient to perform subgroup analysis on TACE and chemotherapy; the downstaging success rate displayed nonsignificant reduction in the TACE group $\left(I^{2}=41.9 \%\right)$ compared to that in the chemotherapy group $\left(I^{2}=80.98 \%\right)(20 \%$ vs. $14 \%$; $p=0.226$; Figure $2 B$ ), and the statistical heterogeneity decreased. Meanwhile, the downstaging rate of combination therapy $\left(I^{2}=96.61 \%\right)$ demonstrated a non-significant trend towards improvement over monotherapy $\left(I^{2}=92.05 \%\right)$ nonsignificantly ( $17 \%$ vs. $12 \%, p=0.338$; Figure 2C). Studies that included patients with cirrhosis $\left(I^{2}=88.13 \%\right)$ had a lower success rate of downstaging than studies that did not, although the difference was not significant $\left(I^{2}=\mathrm{NA}\right)(13 \%$ vs. $17 \%, \mathrm{p}=0.266$; Figure 2D). In addition, extrahepatic spread did not exhibit a link with downstaging rate $\left(I^{2}\right.$ $=83.05 \%)(14 \%$ vs. $11 \%, \mathrm{p}=0.273$; Supplementary Figure 1).

\section{DFS Rate}

Four non-comparative studies with 142 patients investigated the DFS or RFS rate (referred to later in this paper as DFS). Three articles reported 1-year DFS rate; four reported 3-year DFS rates, and two reported 5-year DFS rates. The 1-year DFS rate was $78 \%$ (95\% CI $\left.0.62-0.93, I^{2}=\mathrm{NA}\right), 3$-year DFS rate was $47 \%(95 \% \mathrm{CI}$ $\left.0.25-0.68, I^{2}=79.25 \%\right)$, and the 5 -year DFS rate was $46 \%(95 \%$ CI $0.32-0.59, I^{2}=\mathrm{NA}$ ) (Figure 3).

\section{OS Rate}

Four comparative studies enrolled 492 patients documented data for OS rates (Figure 4). Compared with non-surgical treatment, HR after downstaging therapy showed a significant increase in the 1year OS rate (RR 1.87, 95\% CI 1.48-2.38, $I^{2}=0.0 \%$ ), 2-year OS rate (RR 2.44, 95\% CI 1.06-5.59, $I^{2}=90.6 \%$ ), 3-year OS rate (RR 5.56, 95CI 2.55-12.10, $I^{2}=42.7 \%$ ), 4-year OS rate (RR 5.56, 95\% CI 2.55$12.10, I^{2}=42.7 \%$ ), and 5-year OS rate (RR 5.47, 95\% CI 2.22-13.49, $\left.I^{2}=61.4 \%\right)$. Twelve non-comparative studies investigated the OS rate in 618 patients in 17 subgroups (Figure 5A). Eight articles reported 1-year OS rates, 10 reported 3-year OS rates, and 9 reported 5-year OS rates for 10 subgroups. The 1-year pooled OS rate $\left(I^{2}=73.54 \%\right)$ was $88 \%$ (95\% CI $\left.0.82-0.95\right)$, the 3-year pooled OS rate $\left(I^{2}=6.58 \%\right)$ was $64 \%$ (95\% CI $\left.0.59-0.69\right)$, and the 5 -year combined OS rate $\left(I^{2}=87.13 \%\right)$ was $42 \%$ (95\% CI $\left.0.29-0.54\right)$. Subgroup analysis showed that the 3 -year OS rate of extrahepatic 

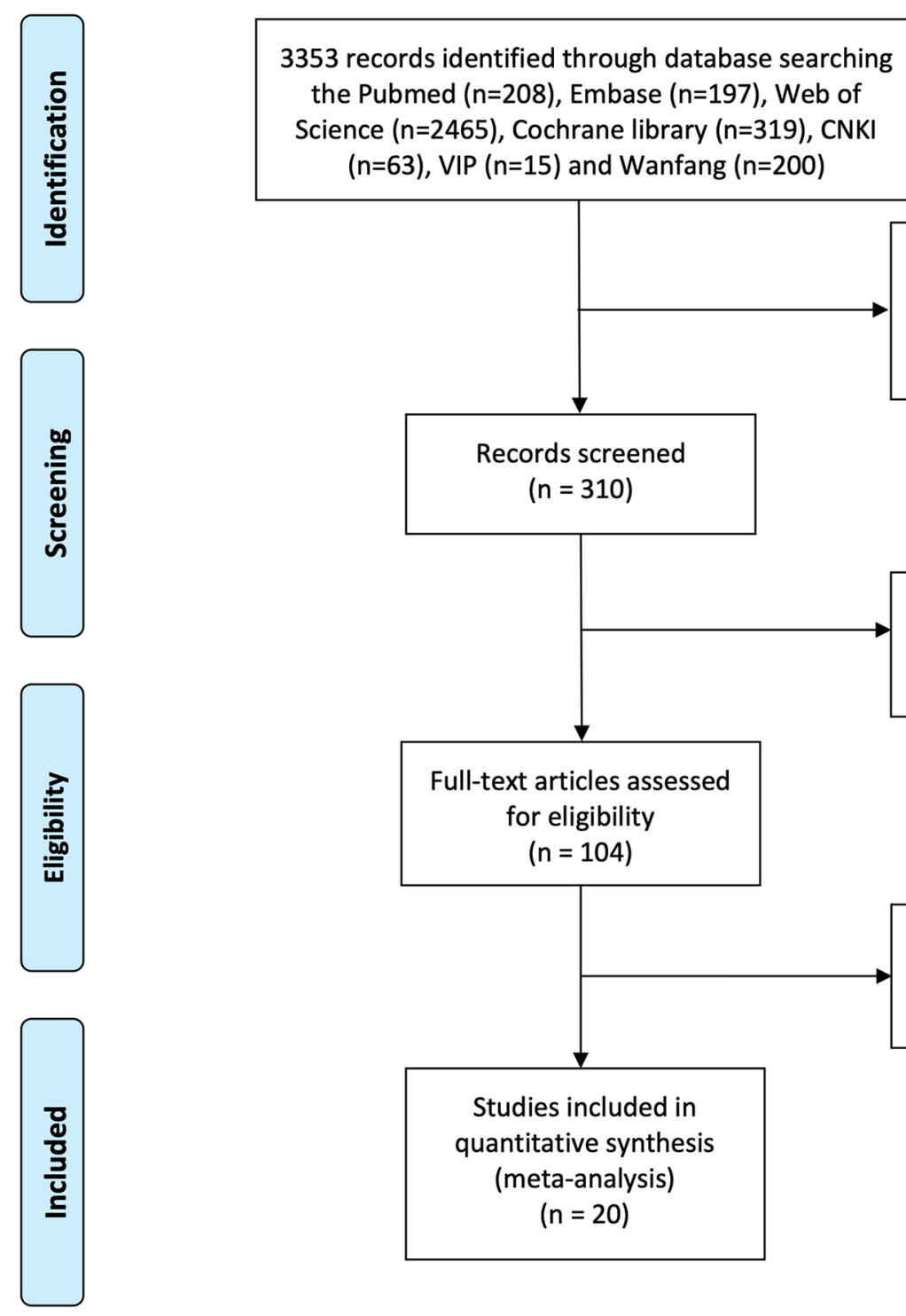

3043 records excluded by reading titles with duplication, irrelevant literature, review, systematic review, case reports

Records excluded by reading abstracts $(n=206)$

Articles excluded by reading full-text

$(n=84)$

FIGURE 1 | Flowchart illustrating the study selection of downstaging prior to HR.

disease was higher than that of the subgroup without extrahepatic disease, but the difference was not statistically significant. The 5-year OS rate in patients with extrahepatic disease was comparable to that in patients without extrahepatic disease (Figures 5C, D). Subgroup analysis by modality for the 5 -year OS rate revealed that the efficacy of multitherapy was better than that of monotherapy $(0.26 v s .0 .06, p$ $=0.02$ ) (Figure 5B).

\section{DISCUSSION}

Unresectable HCC is generally considered incurable. However, the definition of resectable/unresectable is subjective in accordance with the extent of tumor, functional liver reserve, and surgeons' judgments.
Although conversion surgery may be applied following adequate downstaging achieved by tumor downsizing methods or increasing the future liver remnant (FLR), a common criticism is that technically resectable does not represent the optimal oncological outcome. Thus, we conducted this meta-analysis to determine whether downstaging therapies aimed at shrinking tumors are feasible or effective for unresectable intermediate and advanced HCC.

Our meta-analysis is the first to synthesize the existing evidence on the success rates and effectiveness of LRT and/or systemic treatment as downstaging strategies prior to $\mathrm{HR}$ in patients with advanced unresectable HCC, and it confirms that only approximately $14 \%$ of patients attain downstaging after initiation of HR. The chemotherapy, combination, and non-cirrhosis groups exhibited higher rates of downstaging, but these differences were not 
TABLE 1 | Studies of downstaging therapy for hepatic resection of HCC.

\begin{tabular}{|c|c|c|c|c|c|c|}
\hline Study & Year & Intervention & $\begin{array}{c}\text { Types of } \\
\text { intervention }\end{array}$ & $\begin{array}{l}\mathrm{N} \text { of receiving } \\
\text { downstaging }\end{array}$ & Design & Reason of unresectability \\
\hline $\begin{array}{l}\text { Sitzmann } \\
(19)\end{array}$ & 1993 & Combined RT and CT & $\begin{array}{l}\mathrm{LRT}+\text { systemic } \\
\text { treatment }\end{array}$ & 14 & $\begin{array}{l}\text { Retrospective } \\
\text { cohort }\end{array}$ & $\begin{array}{l}\text { Extrahepatic metastasis; diffuse liver tumor or } \\
\text { major vascular invasion }\end{array}$ \\
\hline Majno (20) & 1997 & TACE & LRT & 49 & Case series & Three or more intrahepatic tumor nodules \\
\hline Fan $(21)$ & 1998 & TACE & LRT & 65 & Case series & $\begin{array}{l}\text { Too bulky for resection or situated centrally at } \\
\text { the hepatic hilus }\end{array}$ \\
\hline Lau2 (22) & 2001 & Chemoimmunotherapy & $\begin{array}{l}\text { Systemic } \\
\text { treatment }\end{array}$ & 150 & Case series & $\begin{array}{l}\text { Extrahepatic metastasis; diffuse liver tumor or } \\
\text { major vascular invasion }\end{array}$ \\
\hline $\begin{array}{l}\text { Clavien } \\
\text { (23) }\end{array}$ & 2002 & $\mathrm{CT}$ & $\begin{array}{l}\text { Systemic } \\
\text { treatment }\end{array}$ & $28^{*}$ & $\begin{array}{l}\text { Prospective } \\
\text { pilot study }\end{array}$ & $\begin{array}{l}\text { Diffuse liver tumor; large solitary tumor or major } \\
\text { vascular invasion }\end{array}$ \\
\hline Lau1 (24) & 2004 & $\mathrm{SIR} / \mathrm{CT}$ & $\begin{array}{l}\text { LRT/systemic } \\
\text { treatment }\end{array}$ & $\begin{array}{c}71 \text { (SIR) } \\
124 \text { (PAIF) } \\
75 \text { (doxorubicin) }\end{array}$ & Case series & $\begin{array}{l}\text { Extrahepatic metastasis; diffuse liver tumor or } \\
\text { major vascular invasion }\end{array}$ \\
\hline Tang (25) & 2004 & Multimodality & LRT & $\begin{array}{c}379(\mathrm{HAl}) \\
1085(\mathrm{HAl}+\mathrm{HAL}) \\
562(\mathrm{HAl}+\mathrm{HAL} \\
+\mathrm{RAIT})\end{array}$ & Case series & NA \\
\hline Zhao (26) & 2009 & TACE or TACE+PEI or TACE-RT & LRT & 34 & Case series & $\begin{array}{l}\text { Too bulky for resection; diffuse liver tumor or } \\
\text { major vascular invasion }\end{array}$ \\
\hline Shi $(27)$ & 2012 & TACE & LRT & 412 & Case series & $\begin{array}{l}\text { Too bulky for resection or located centrally at } \\
\text { the hepatic hilus }\end{array}$ \\
\hline Chen (28) & 2013 & TACE & LRT & 433 & Case series & NA \\
\hline $\begin{array}{l}\text { Kaseb } \\
\text { (29) }\end{array}$ & 2013 & CT (mPAIF vs. PAIF) & $\begin{array}{l}\text { Systemic } \\
\text { treatment }\end{array}$ & 117 (33 vs. 84) & $\begin{array}{l}\text { Retrospective } \\
\text { cohort }\end{array}$ & $\begin{array}{l}\text { Extrahepatic metastasis; diffuse liver tumor or } \\
\text { major vascular invasion }\end{array}$ \\
\hline Lee1 (30) & 2014 & $\begin{array}{l}\text { HAI+CCRT followed by resection vs. } \\
\text { HAI+CCRT alone }\end{array}$ & LRT & 243 (41 vs. 202) & $\begin{array}{l}\text { Retrospective } \\
\text { cohort }\end{array}$ & $\begin{array}{l}\text { Too bulky for resection; diffuse liver tumor or } \\
\text { major vascular invasion }\end{array}$ \\
\hline Lee2 (31) & 2014 & CCRT & LRT & 41 & $\begin{array}{l}\text { Retrospective } \\
\text { cohort }\end{array}$ & Too bulky for resection; major vascular invasion \\
\hline $\begin{array}{l}\text { Zhang } \\
(32)\end{array}$ & 2016 & TACE-RT & LRT & 82 (43 vs. 39) & $\begin{array}{l}\text { Retrospective } \\
\text { cohort }\end{array}$ & NA \\
\hline Li (33) & 2017 & TACE+sorafinib & $\begin{array}{l}\mathrm{LRT}+\text { systemic } \\
\text { treatment }\end{array}$ & 21 & Case series & BCLC stage B-C \\
\hline $\begin{array}{l}\text { Hamaoka } \\
(34)\end{array}$ & 2017 & $\begin{array}{l}\text { HAl+RT followed by resection vs. HAl } \\
+\mathrm{RT} \text { alone }\end{array}$ & LRT & 50 (7 vs. 43) & $\begin{array}{l}\text { Retrospective } \\
\text { cohort }\end{array}$ & HCC with PVTा \\
\hline He (35) & 2018 & HAl+sorafenib & $\begin{array}{l}\mathrm{LRT}+\text { systemic } \\
\text { treatment }\end{array}$ & 35 & $\begin{array}{l}\text { Prospective } \\
\text { single-arm }\end{array}$ & Extrahepatic metastasis; HCC with PVTT \\
\hline Lee3 (36) & 2019 & $\mathrm{HAl}$ & LRT & 103 & Case series & $\begin{array}{l}\text { Extrahepatic metastasis; diffuse liver tumor or } \\
\text { major vascular invasion }\end{array}$ \\
\hline Goto (37) & 2020 & $\mathrm{HAl}$ & LRT & 18 & $\begin{array}{l}\text { Retrospective } \\
\text { cohort }\end{array}$ & Diffuse liver tumor or major vascular invasion \\
\hline Chiu (38) & 2020 & DEB-TACE vs. cTACE & LRT & $61(42$ vs. 19) & $\begin{array}{l}\text { Retrospective } \\
\text { cohort }\end{array}$ & Diffuse liver tumor or major vascular invasion \\
\hline
\end{tabular}

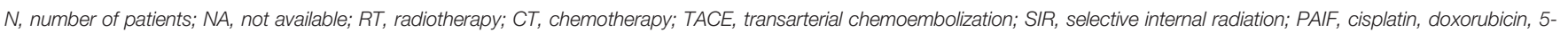

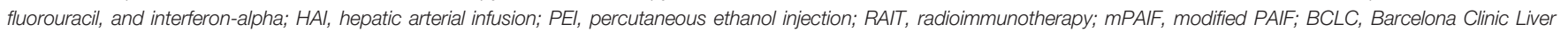
Cancer; DEB-TACE, drug-eluting beads transarterial chemoembolization; cTACE, conventional transarterial chemoembolization.

*5 HCC and 23 metastatic colorectal cancer.

significant. The conversion rate of HR is much lower than that of LT (39), which remains unsatisfactory. This might be explained by the fact that studies on downstaging for HR were fewer in number and of poorer quality compared to studies of LT, which often included LRT as a bridge to transplantation, and some studies enrolled patients who failed previous treatment. There is significant heterogeneity in terms of different inclusion criteria of downstaging, subjective judgment of resectability, and the selection of LRT, which is closely related to the experiences and preferences of each institution. In comparative studies, the OS rates of resection after downstaging were notably better than those in patients receiving LRT or systemic treatment alone at 1 year (RR 1.87, 95\% CI 1.48-2.38), 3 years (RR 5.56, 95\% CI 2.55-12.10), and 5 years (RR 5.47, 95\% CI 2.22-13.49). In comparative studies, the pooled DFS rates of patients undergoing HR after successful downstaging were $78 \%$ (95\% CI $0.62-0.93)$ at 1 year, $47 \%(95 \%$ CI $0.25-0.68)$ at 3 years, and $46 \%(95 \%$ CI $0.32-0.59)$ at 5 years. The pooled OS rates were $88 \%$ (95\% CI $0.82-0.95)$ at 1 year, $64 \%(95 \%$ CI $0.59-0.69)$ at 3 years, and $42 \%$ (95\% CI $0.29-0.54)$ at 5 years. These results were better than the reported data of non-surgical interventions (40), and worse than the industry-accepted survival rates of early HCC (4). As a result, downstaging may be considered an alternative strategy for patients with unresectable HCC. In this paper, downstaging is defined as systemic therapy or regional antitumor therapy with the aim of converting unresectable HCC into resectable HCC. It is necessary to optimize the downstaging strategies to further improve the effect from an intent-to-treat viewpoint. Although many studies have investigated the clinical 
A

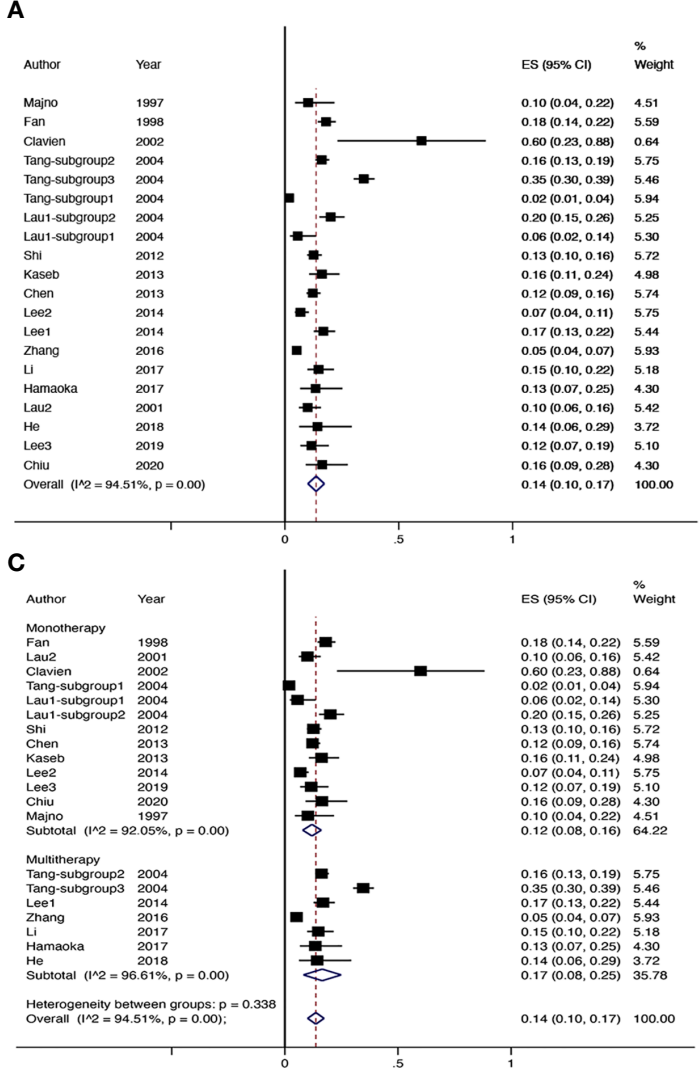

B

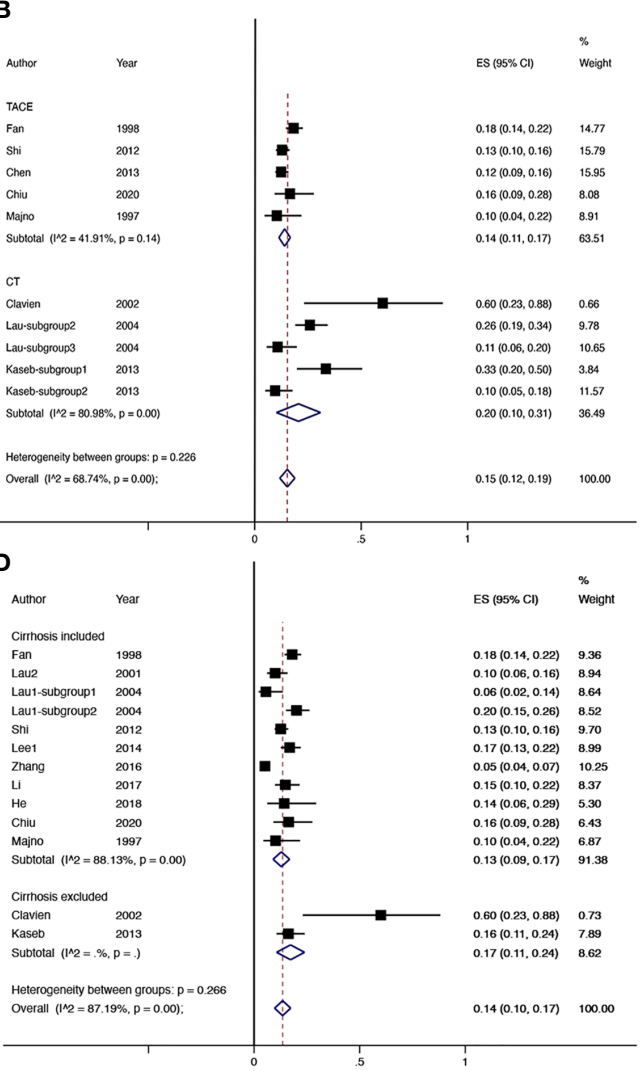

FIGURE 2 | The overall downstaging success rate of hepatic resection of HCC (A), pooled downstaging rate stratified by TACE and CT (B), pooled downstaging rate stratified by mono/multitherapy (C); pooled downstaging rate stratified by cirrhosis included/excluded (D). TACE, transarterial chemoembolization; CT, chemotherapy.

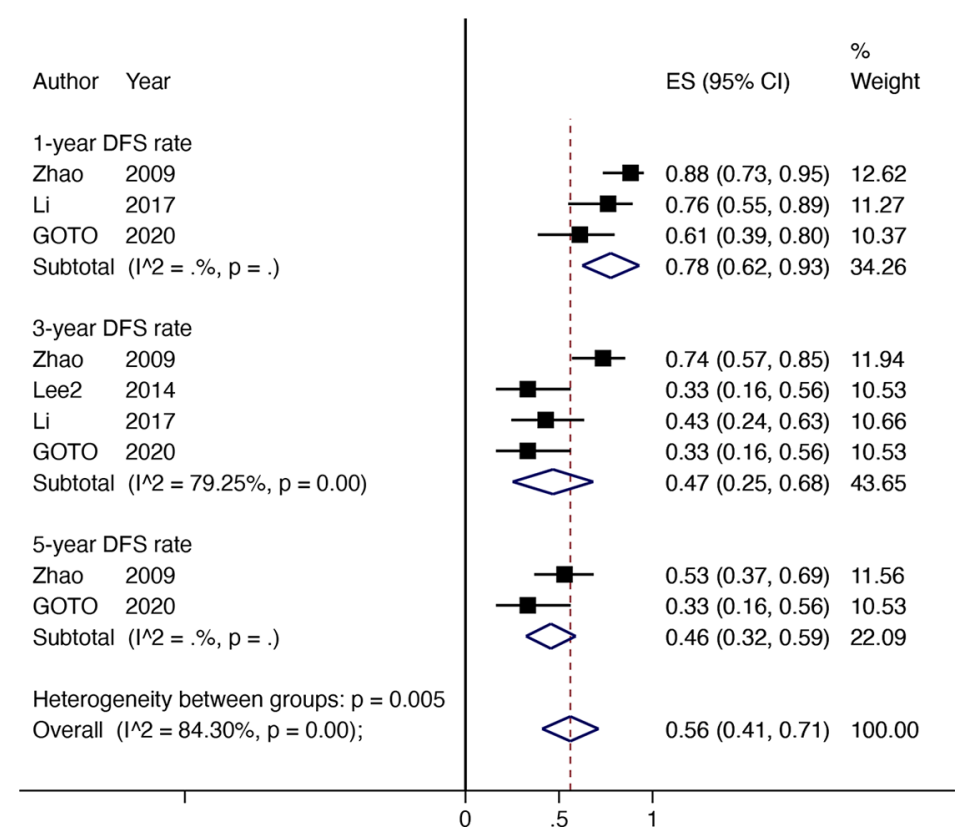

FIGURE 3 | The DFS rate for HR with downstaging therapies in patients with HCC. 


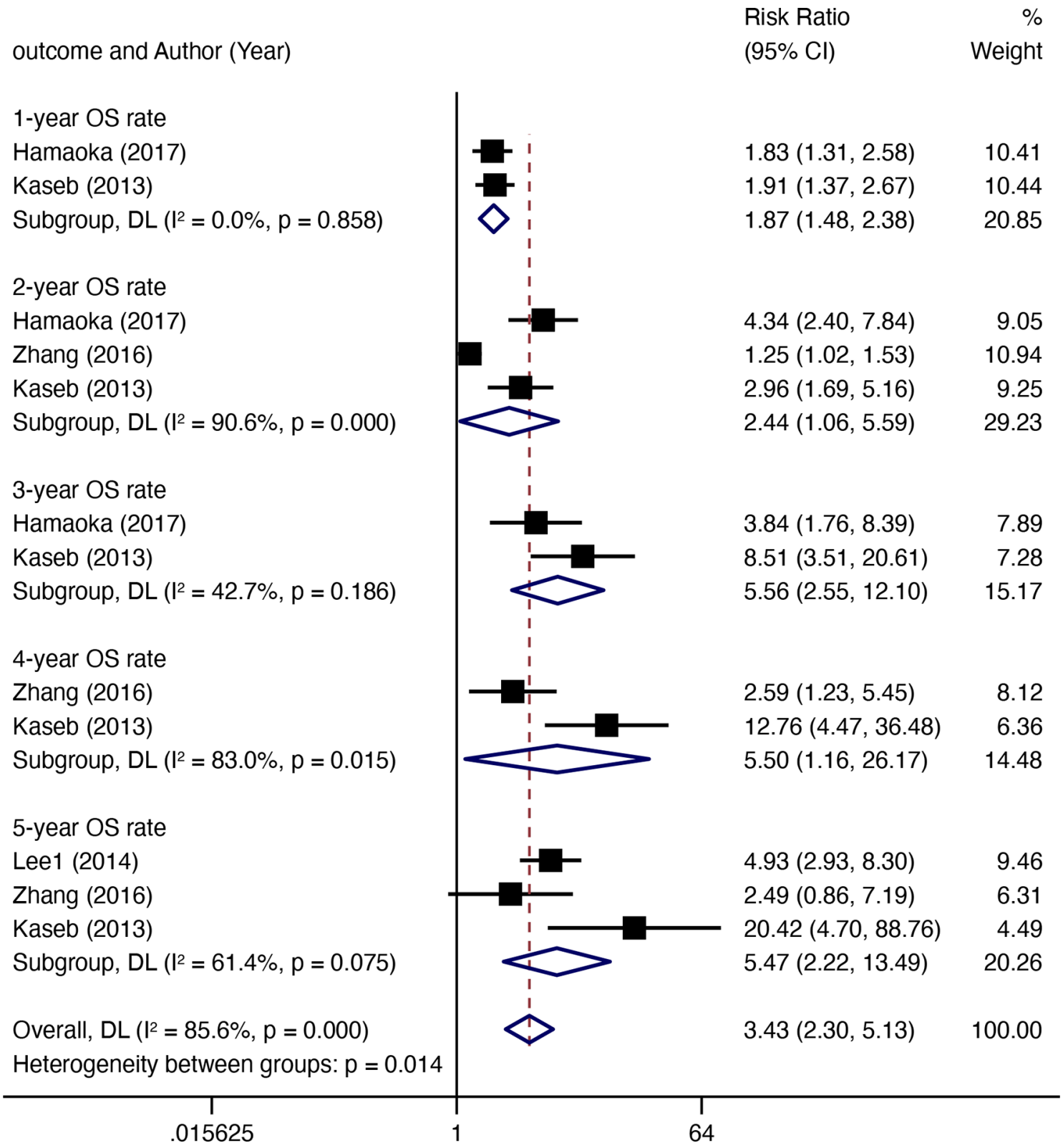

FIGURE 4 | The OS rate (resection after downstaging versus LRT or systematic treatment alone) for HR with downstaging therapies in patients with HCC.

efficacy of LRT or systemic therapy alone for unresectable HCC, the best intervention for downstaging therapy is not yet clear. The causes of unresectability varied in different studies, mainly including local extension, major vascular invasion, and extrahepatic spread. LRTs such as TACE, SIR, and HAI tend to be adopted in patients with local extension and major vascular invasion. TACE is considered a standard care for unresectable HCC and has also been widely used in downstaging strategies. Recently, TARE/SIR, as an alternative to TACE, has received increasing attention because it can effectively shrink a tumor and shorten the response time, and may be adopted for the patients of portal thrombosis (a contraindication of TACE) (41). Microwave and radiofrequency ablation have been used in LT downstaging, but there are no related reports on HR downstaging. Six articles reported patients with extrahepatic metastases, mainly using systemic treatment. LRT was only employed in one study, which showed that extrahepatic metastasis was not a significant factor in survival for patients with HAI with chemotherapy (36). The use of HAI with chemotherapy in HCC patients with minimal extrahepatic metastasis was supported in previous studies, for intrahepatic lesions have a greater impact on survival than extrahepatic lesions (42-44). Based on our meta-analysis, extrahepatic metastasis was not 


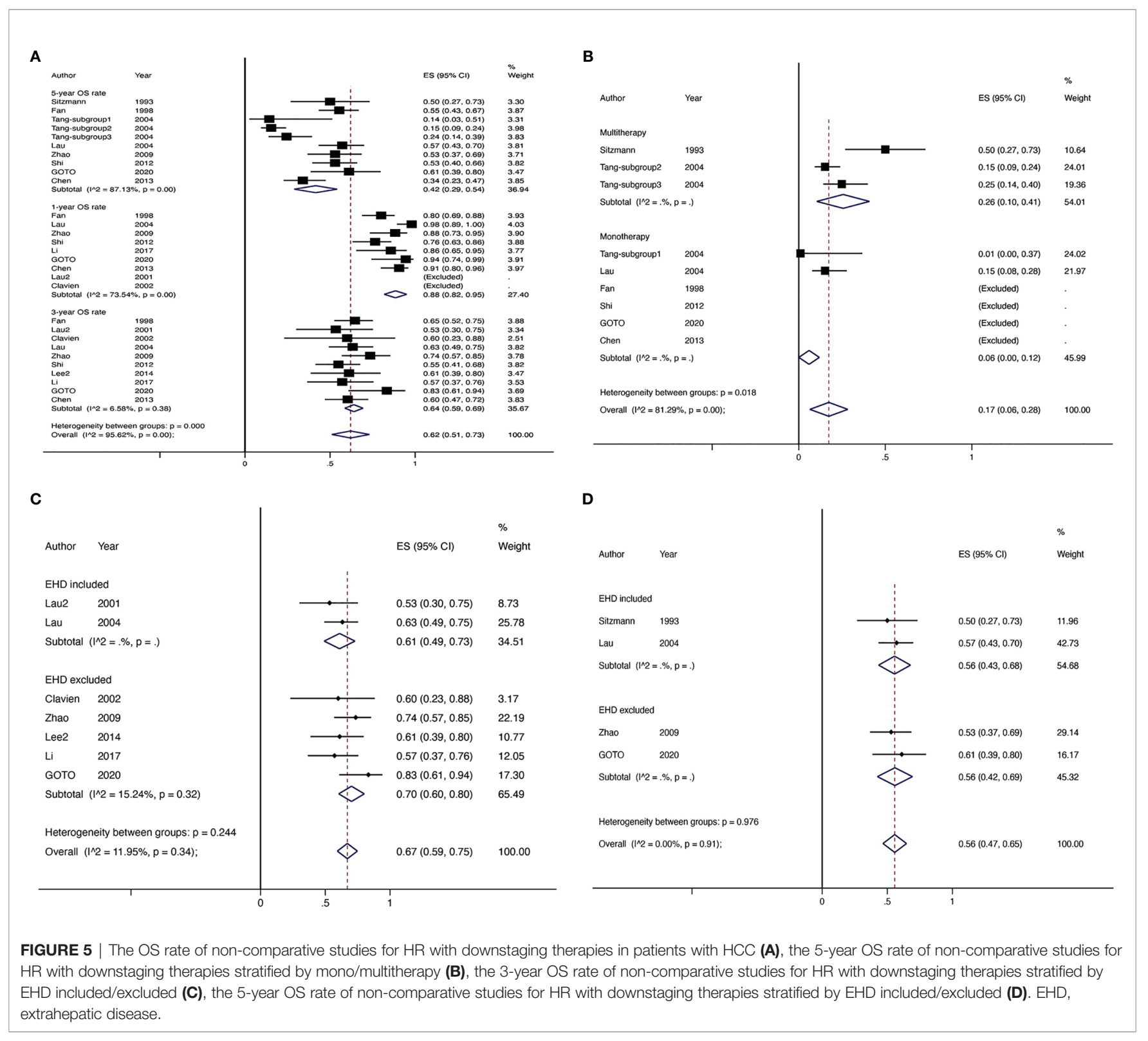

associated with the 3- and 5-year OS rate. Furthermore, the subgroup analyses of the downstaging rate on intervention and patients with or without cirrhosis showed no significant difference in the downstaging rate, while these data were insufficient for subgroup analysis on survival. Notably, the subgroup analysis of mono/multitherapy showed that multimodality downstaging prolongs long-term survival. This suggests that the results may not be affected by the selection of downstaging therapy, but more influenced by whether the combination of downstaging therapy is implemented.

Another important issue is the endpoint of downstaging and criteria for post-downstaging liver resection, which must be defined more precisely. It is generally believed that a reduction in tumor size may be an effective evaluation indication $(20,21,34)$. A few researchers have adopted the criteria of partial remission (PR) for resection after downstaging $(21,27)$. However, whether the subsequent HR needs to be removed when the tumor disappears on imaging remains controversial. Shi et al. (2012) considered that surgical resection should be performed under these conditions because clinical complete response (CR) does not represent pathological CR (27). Residual viable cancer cells may lead to a high recurrence rate (10). According to Hamaoka et al. (2017) (34) and Lee et al. (2019) (36), successful conversion to surgery is considered to be a factor of favorable prognosis. In contrast, Zhang et al. (2016) reported that salvage surgery after TACE for unresectable HCC has an OS benefit only in patients with a PR to TACE, while those achieving CR group do not show improvement (32). This might be due to the role of downstaging in the selection of biological aggression. The presence of vascular invasion, multiple tumors, and high alpha-fetoprotein levels are regarded as risk 
factors of survival in patients with resectable HCC as well as downstaging $(2,21,31,35)$. Therefore, downstaging may serve as a screening tool to identify patients who might benefit from surgery. Since conventional criteria for HR are based on HCC morphology, downstaging, which can predict HCC biology, will be more favorable.

The limitation of high heterogeneity among different downstaging strategies for HCC should also be considered. The selection of a treatment strategy is based merely on the habit at a single center. Additionally, no RCT has been performed; therefore, the grade of evidence was weak.

To date, there has been surrounding the best strategy for unresectable HCC. The evidence of HR mainly came from small published series, having demonstrated useful attempts. Based on this meta-analysis, operable patients with unresectable HCC may be screened for downstaging. Surgical resection after successful downstaging can maximize the improvements in the prognosis of patients with unresectable HCC, bringing hope for patients initially considered incurable. With the rapid advancements in LRT in recent years, the emergence of novel targeted therapies, especially immunotherapy, has tremendously facilitated nonsurgical treatments for HCC, suggesting a potential role for downstaging. In the future, prospective trials with large sample sizes on these new methods are expected to provide reasonable guidance and inspire more effective strategies for downstaging approaches. Future criteria should include a clear downstaging endpoint and molecular biological information and markers.

\section{DATA AVAILABILITY STATEMENT}

The raw data supporting the conclusions of this article will be made available by the authors, without undue reservation.

\section{REFERENCES}

1. Bray F, Ferlay J, Soerjomataram I, Siegel RL, Torre LA, Jemal A. Global Cancer Statistics 2018: GLOBOCAN Estimates of Incidence and Mortality Worldwide for 36 Cancers in 185 Countries. CA: Cancer J Clin (2018) 68 (6):394-424. doi: 10.3322/caac.21492

2. EASL Clinical Practice Guidelines. Management of Hepatocellular Carcinoma. J Hepatol (2018) 69(1):182-236. doi: 10.1016/j.jhep.2018.03.019

3. Marrero JA, Kulik LM, Sirlin CB, Zhu AX, Finn RS, Abecassis MM, et al. Diagnosis, Staging, and Management of Hepatocellular Carcinoma: 2018 Practice Guidance by the American Association for the Study of Liver Diseases. Hepatol (Baltimore Md) (2018) 68(2):723-50. doi: 10.1002/hep.29913

4. Benson AB, D'Angelica MI, Abbott DE, Abrams TA, Alberts SR, Anaya DA, et al. Et Al: Guidelines Insights: Hepatobiliary Cancers, Version 2.2019. J Natl Compr Canc Netw (2019) 17(4):302-10. doi: 10.6004/jnccn.2019.0019

5. Llovet JM, Bru C, Bruix J. Prognosis of Hepatocellular Carcinoma: The BCLC Staging Classification. Semin Liver Dis (1999) 19(3):329-38. doi: 10.1055/s2007-1007122

6. Zhong JH, Ke Y, Gong WF, Xiang BD, Ma L, Ye XP, et al. Hepatic Resection Associated With Good Survival for Selected Patients With Intermediate and Advanced-Stage Hepatocellular Carcinoma. Ann Surg (2014) 260(2):329-40. doi: 10.1097/SLA.0000000000000236

7. Torzilli G, Belghiti J, Kokudo N, Takayama T, Capussotti L, Nuzzo G, et al. A Snapshot of the Effective Indications and Results of Surgery for Hepatocellular Carcinoma in Tertiary Referral Centers: Is it Adherent to the EASL/AASLD

\section{ETHICS STATEMENT}

Ethical review and approval was not required for the study on human participants in accordance with the local legislation and institutional requirements. Written informed consent for participation was not required for this study in accordance with the national legislation and the institutional requirements.

\section{AUTHOR CONTRIBUTIONS}

Conceptualization: LeL and JY. Study selection and data extraction: XC and LiL. Statistical analysis: XC. Writingoriginal draft: XC and LiL. Writing-review and editing: LeL and JY. Final approval of the manuscript: all authors. All authors contributed to the article and approved the submitted version.

\section{FUNDING}

This research was supported by the Basic Ability Enhancement Program for Young and Middle-aged Teachers in Higher Education Institutions of Guangxi (Nos. 2021KY0091 and 2021KY0283) and the Science Foundation for Distinguished Young Scholars of Guangxi University of Chinese Medicine (Grant No. 2020JQ001).

\section{SUPPLEMENTARY MATERIAL}

The Supplementary Material for this article can be found online at: https://www.frontiersin.org/articles/10.3389/fonc.2021. 740762/full\#supplementary-material

Recommendations? An Observational Study of the HCC East-West Study Group Ann Surg (2013) 257(5):929-37. doi: 10.1097/SLA.0b013e31828329b8

8. Glantzounis GK, Paliouras A, Stylianidi MC, Milionis H, Tzimas P, Roukos D, et al. The Role of Liver Resection in the Management of Intermediate and Advanced Stage Hepatocellular Carcinoma. A Systematic Review. Eur J Surg Oncol (2018) 44(2):195-208. doi: 10.1016/j.ejso.2017.11.022

9. Omata M, Cheng AL, Kokudo N, Kudo M, Lee JM, Jia J, et al. Asia-Pacific Clinical Practice Guidelines on the Management of Hepatocellular Carcinoma: A 2017 Update. Hepatol Int (2017) 11(4):317-70. doi: 10.1007/ s12072-017-9799-9

10. Lau WY, Lai EC. Salvage Surgery Following Downstaging of Unresectable Hepatocellular Carcinoma-A Strategy to Increase Resectability. Ann Surg Oncol (2007) 14(12):3301-9. doi: 10.1245/s10434-007-9549-7

11. Liberati A, Altman DG, Tetzlaff J, Mulrow C, Gøtzsche PC, Ioannidis JPA, et al. The PRISMA Statement for Reporting Systematic Reviews and MetaAnalyses of Studies That Evaluate Healthcare Interventions: Explanation and Elaboration. BMJ (2009) 339:b2700. doi: 10.1136/bmj.b2700

12. Stroup DF, Berlin JA, Morton SC, Olkin I, Williamson GD, Rennie D, et al. Meta-Analysis of Observational Studies in Epidemiology: A Proposal for Reporting. Meta-Analysis Of Observational Studies in Epidemiology (MOOSE) Group. JAMA (2000) 283(15):2008-12. doi: 10.1001/ jama.283.15.2008

13. Higgins JPT, Altman DG, Gøtzsche PC, Jüni P, Moher D, Oxman AD, et al. The Cochrane Collaboration's Tool for Assessing Risk of Bias in Randomised Trials. BMJ (2011) 343:d5928. doi: 10.1136/bmj.d5928 
14. Gates M, Gates A, Duarte G, Cary M, Becker M, Prediger B, et al. Quality and Risk of Bias Appraisals of Systematic Reviews are Inconsistent Across Reviewers and Centers. J Clin Epidemiol (2020) 125:9-15. doi: 10.1016/j.jclinepi.2020.04.026

15. Stang A. Critical Evaluation of the Newcastle-Ottawa Scale for the Assessment of the Quality of Nonrandomized Studies in Meta-Analyses. Eur J Epidemiol (2010) 25(9):603-5. doi: 10.1007/s10654-010-9491-z

16. Kishi Y, Shimada K, Nara S, Esaki M, Kosuge T. Role of Hepatectomy for Recurrent or Initially Unresectable Hepatocellular Carcinoma. World J Hepatol (2014) 6(12):836-43. doi: 10.4254/wjh.v6.i12.836

17. Higgins J, Thompson S, Deeks J, Altman D. Statistical Heterogeneity in Systematic Reviews of Clinical Trials: A Critical Appraisal of Guidelines and Practice. J Health Serv Res Policy (2002) 7(1):51-61. doi: 10.1258/1355819021927674

18. JPT Higgins, J Thomas, J Chandler, M Cumpston, T Li, MJ Page and VA Welch eds. Cochrane Handbook for Systematic Reviews of Interventions Version 6.2 (Updated February 2021). In: Cochrane Handbook for Systematic Reviews of Interventions Chichester (UK): John Wiley \& Sons (2019). Available at: www.training.cochrane.org/handbook.

19. Sitzmann JV, Abrams R. Improved Survival for Hepatocellular Cancer With Combination Surgery and Multimodality Treatment. Ann Surg (1993) 217 (2):149-54. doi: 10.1097/00000658-199302000-00009

20. Majno PE, Adam R, Bismuth H, Castaing D, Ariche A, Krissat J, et al. Influence of Preoperative Transarterial Lipiodol Chemoembolization on Resection and Transplantation for Hepatocellular Carcinoma in Patients With Cirrhosis. Ann Surg (1997) 226(6):688-701; discussion 701-683. doi: 10.1097/00000658-199712000-00006

21. Fan J, Tang ZY, Yu YQ, Wu ZQ, Ma ZC, Zhou XD, et al. Improved Survival With Resection After Transcatheter Arterial Chemoembolization (TACE) for Unresectable Hepatocellular Carcinoma. Dig Surg (1998) 15(6):674-8. doi: 10.1159/000018676

22. Lau WY, Leung TW, Lai BS, Liew CT, Ho SK, Yu SC, et al. Preoperative Systemic Chemoimmunotherapy and Sequential Resection for Unresectable Hepatocellular Carcinoma. Ann Surg (2001) 233(2):236-41. doi: 10.1097/ 00000658-200102000-00013

23. Clavien PA, Selzner N, Morse M, Selzner M, Paulson E. Downstaging of Hepatocellular Carcinoma and Liver Metastases From Colorectal Cancer by Selective Intra-Arterial Chemotherapy. Surgery (2002) 131(4):433-42. doi: 10.1067/msy.2002.122374

24. Lau WY, Ho SK, Yu SC, Lai EC, Liew CT, Leung TW. Salvage Surgery Following Downstaging of Unresectable Hepatocellular Carcinoma. Ann Surg (2004) 240(2):299-305. doi: 10.1097/01.sla.0000133123.11932.19

25. Tang ZY, Zhou XD, Ma ZC, Wu ZQ, Fan J, Qin LX, et al. Downstaging Followed by Resection Plays a Role in Improving Prognosis of Unresectable Hepatocellular Carcinoma. Hepatobil Pancreat Dis Int (2004) 3(4):495-8.

26. Zhao HT. Analysis of the Curative Effect of Resection After Downstaging of Unresectable Advanced Liver Cancer. Acta Acad Med Sinic (2009) 31(4):5035. doi: 10.3881/j.issn.1000-503X.2009.04.024

27. Shi XJ, Jin X, Wang MQ, Wei LX, Ye HY, Liang YR, et al. Effect of Resection Following Downstaging of Unresectable Hepatocelluar Carcinoma by Transcatheter Arterial Chemoembolization. Chin Med J (Engl) (2012) 125 (2):197-202. doi: 10.3760/cma.j.issn.0366-6999.2012.02.007

28. Chen ZY, Du J, Zhao YM, Shi GJ. The Effect of Hepatectomy After Transcatheter Hepatic Arterial Chemoembolization for the Treatment of Patients With Advanced Primary Liver Cancer. Electronic J Clin Gen Surg (2013) 2):47-50.

29. Kaseb AO, Shindoh J, Patt YZ, Roses RE, Zimmitti G, Lozano RD, et al. Modified Cisplatin/Interferon Alpha-2b/Doxorubicin/5-Fluorouracil (PIAF) Chemotherapy in Patients With No Hepatitis or Cirrhosis is Associated With Improved Response Rate, Resectability, and Survival of Initially Unresectable Hepatocellular Carcinoma. Cancer (2013) 119(18):3334-42. doi: 10.1002/cncr.28209

30. Lee HS, Choi GH, Choi JS, Kim KS, Han KH, Seong J, et al. Surgical Resection After Down-Staging of Locally Advanced Hepatocellular Carcinoma by Localized Concurrent Chemoradiotherapy. Ann Surg Oncol (2014) 21 (11):3646-53. doi: 10.1245/s10434-014-3652-3

31. Lee IJ, Kim JW, Han KH, Kim JK, Kim KS, Choi JS, et al. Concurrent Chemoradiotherapy Shows Long-Term Survival After Conversion From Locally Advanced to Resectable Hepatocellular Carcinoma. Yonsei Med J (2014) 55(6):1489-97. doi: 10.3349/ymj.2014.55.6.1489

32. Zhang Y, Huang G, Wang Y, Liang L, Peng B, Fan W, et al. Is Salvage Liver Resection Necessary for Initially Unresectable Hepatocellular Carcinoma Patients
Downstaged by Transarterial Chemoembolization? Ten Years of Experience. Oncologist (2016) 21(12):1442-9. doi: 10.1634/theoncologist.2016-0094

33. Li CJ, Zhou J. The Primary Report of Hepatectomy After Transcatheter Hepatic Arterial Chemoembolization Combined With Sorafinib. Fu Bu Wai Ke (2017) 30(4):65-68+71. doi: 10.3969/j.issn.1003-5591.2017.04.015

34. Hamaoka M, Kobayashi T, Kuroda S, Iwako H, Okimoto S, Kimura T, et al. Hepatectomy After Down-Staging of Hepatocellular Carcinoma With Portal Vein Tumor Thrombus Using Chemoradiotherapy: A Retrospective Cohort Study. Int J Surg (2017) 44:223-8. doi: 10.1016/j.ijsu.2017.06.082

35. He MK, Zou RH, Li QJ, Zhou ZG, Shen JX, Zhang YF, et al. Phase II Study of Sorafenib Combined With Concurrent Hepatic Arterial Infusion of Oxaliplatin, 5-Fluorouracil and Leucovorin for Unresectable Hepatocellular Carcinoma With Major Portal Vein Thrombosis. Cardiovasc Intervent Radiol (2018) 41(5):734-43. doi: 10.1007/s00270-017-1874-z

36. Lee B-H, Lee D-S, Cho CW, Yun S-S. Role and Limitation of Neoadjuvant Hepatic Arterial Infusion Chemotherapy in Advanced Hepatocelluar Carcinoma Patients With Child-Pugh Class A. World J Surg Oncol (2019) 17(1):143. doi: 10.1186/s12957-019-1685-6

37. Goto Y, Hisaka T, Sakai H, Takagi K, Fukutomi S, Akagi Y, et al. Salvage Surgery for Initially Unresectable Locally Advanced Hepatocellular Carcinoma Downstaged by Hepatic Arterial Infusion Chemotherapy. Anticancer Res (2020) 40(8):4773-7. doi: 10.21873/anticanres.14479

38. Chiu S-H, Chang P-Y, Shih Y-L, Huang W-Y, Ko K-H, Chang W-C, et al. Efficacy and Safety of Supplemental Transarterial Chemoembolization Through Extrahepatic Collateral Arteries With Drug-Eluting Beads: Treatment for Unresectable Hepatocellular Carcinoma. Drug Des Devel Ther (2020) 14:5029-41. doi: 10.2147/DDDT.S266470

39. Kulik L, Heimbach JK, Zaiem F, Almasri J, Prokop LJ, Wang Z, et al. Therapies for Patients With Hepatocellular Carcinoma Awaiting Liver Transplantation: A Systematic Review and Meta-Analysis. Hepatology (2018) 67(1):381-400. doi: 10.1002/hep.29485

40. Takayasu K, Arii S, Ikai I, Omata M, Okita K, Ichida T, et al. Prospective Cohort Study of Transarterial Chemoembolization for Unresectable Hepatocellular Carcinoma in 8510 Patients. Gastroenterology (2006) 131 (2):461-9. doi: 10.1053/j.gastro.2006.05.021

41. Rognoni C, Ciani O, Sommariva S, Facciorusso A, Tarricone R, Bhoori S, et al. Trans-Arterial Radioembolization in Intermediate-Advanced Hepatocellular Carcinoma: Systematic Review and Meta-Analyses. Oncotarget (2016) 7 (44):72343-55. doi: 10.18632/oncotarget.11644

42. Yamasaki T, Kimura T, Kurokawa F, Aoyama K, Ishikawa T, Tajima K, et al. Prognostic Factors in Patients With Advanced Hepatocellular Carcinoma Receiving Hepatic Arterial Infusion Chemotherapy. J Gastroenterol (2005) 40 (1):70-8. doi: 10.1007/s00535-004-1494-7

43. Shao YY, Huang CC, Liang PC, Lin ZZ. Hepatic Arterial Infusion of Chemotherapy for Advanced Hepatocellular Carcinoma. Asia Pac J Clin Oncol (2010) 6(2):80-8. doi: 10.1111/j.1743-7563.2010.01287.x

44. Song DS, Bae SH, Song MJ, Lee SW, Kim HY, Lee YJ, et al. Hepatic Arterial Infusion Chemotherapy in Hepatocellular Carcinoma With Portal Vein Tumor Thrombosis. World J Gastroenterol (2013) 19(29):4679-88. doi: 10.3748/wjg.v19.i29.4679

Conflict of Interest: The authors declare that the research was conducted in the absence of any commercial or financial relationships that could be construed as a potential conflict of interest.

Publisher's Note: All claims expressed in this article are solely those of the authors and do not necessarily represent those of their affiliated organizations, or those of the publisher, the editors and the reviewers. Any product that may be evaluated in this article, or claim that may be made by its manufacturer, is not guaranteed or endorsed by the publisher.

Copyright (๑) 2021 Chen, Lai, Ye and Li. This is an open-access article distributed under the terms of the Creative Commons Attribution License (CC BY). The use, distribution or reproduction in other forums is permitted, provided the original author(s) and the copyright owner(s) are credited and that the original publication in this journal is cited, in accordance with accepted academic practice. No use, distribution or reproduction is permitted which does not comply with these terms. 